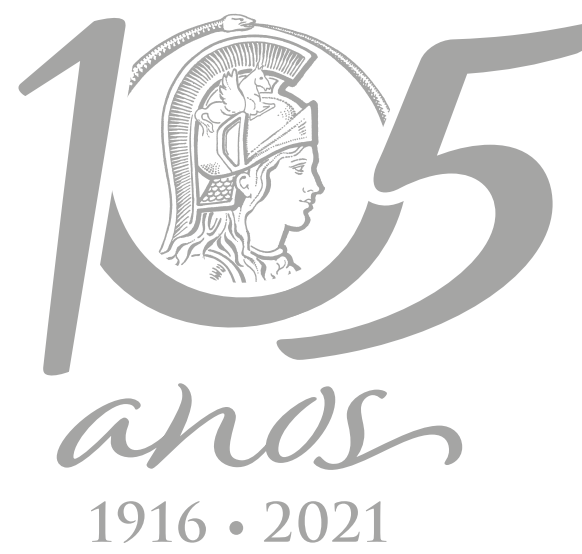

\title{
Analyses of the response of carbapenem- resistant Pseudomonas aeruginosa against monotherapy and combined therapy using quantum dots and proteomics
}

\author{
JAILTON L.C. LIMA, JUSSYÊGLES N.P. PEREIRA, BRUNO L. RAPOSO, \\ ADRIANA FONTES, PAULO E. CABRAL FILHO, REGINALDO G. LIMA NETO, \\ RAFAEL M. XIMENES \& MARIA AMÉLIA V. MACIEL
}

\begin{abstract}
Carbapenem-resistant $P$. aeruginosa (CRPA) has become a serious public health problem and the biofilm formation aggravates this problem. The study aimed to evaluate the occurrence of $\beta$-lactamases and quorum sensing (QS) genes in CRPA isolates, analyze production of biofilm, evaluate the response against meropenem (MPM) andor polymyxin B (POL B) and its association with azythromicin (AZT) using quantum dots (QDS) and proteomic analysis. Six CRPA isolates were analyzed. $\beta$-lactamases and QS genes were search using specific PCRs and were tested for biofilm production by quantitative technique. A CRPA isolate, containing blaKPC gene and biofilm-producing, was selected to assess its response to therapy using QDS and the MALDI-TOF. The $\beta$-lactamase detected was blaKPC in $66.7 \%$ of the isolates. All isolates were biofilm producers and carriers of the QS genes. QDs-MPM conjugates triggered the formation of biofilm and the association with AZT inhibited this effect. Proteomics analysis showed that treatments with MPM or POL B suppressed the expression of the transglycosylase protein, while combined therapy with AZT induced expression of the RpoN protein. Thus, this study shows that the use of fluorescence combined with the proteomics analysis was promising to understand how a CRPA strain reacts to antimicrobial treatment.
\end{abstract}

Key words: biofilm, drug resistance, fluorescence, RpoN, transglycosylase.

\section{INTRODUCTION}

Pseudomonas aeruginosa is a ubiquitous microorganism, able to adapt to diverse environments and acquire different resistance mechanisms, causing different types of infections, mainly in immunosuppressed patients or those with co-morbidities. Besides, the indiscriminate use of antimicrobials to treat infections caused by this microorganism has selected and spread worldwide multidrugresistant (MDR) or extensively drug-resistant (XDR) P. aeruginosa high-risk clones. These are critical public health problems due to the limitation of effective and safe treatments, being the combination of polymyxin $\mathrm{B}$ ( $\mathrm{POL}$ $B$ ) with another antimicrobial drug one of the few possible therapeutic options (Doi 2019, Horcajada et al. 2019, Montero et al. 2019).

Moreover, carbapenem antibiotics are a class of $\beta$-lactam antimicrobials widely used to treat infections by gram-negative bacteria, acting in the inhibition of bacterial cell wall synthesis, through binding to penicillinbinding proteins (PBPS), being meropenem (MPM) more effective than imipenem against 
P. aeruginosa strains. Another advantage of these antimicrobials is their stability against a broad-spectrum of $\beta$-lactamase enzymes $(E S B L)$, although they are hydrolyzed by the enzyme Klebsiella pneumoniae carbapenemase (KPC), which has greater hydrolytic power. Due to the emergence of strains of carbapenemresistant $P$. aeruginosa (CRPA), there has been a limitation of therapeutic options, suggesting the use of combinations of antimicrobials against these strains, which may include the use of $\beta$-lactam with $\beta$-lactamase inhibitors, polymyxins, aminoglycosides and even the use of meropenem (Horcajada et al. 2019, Montero et al. 2019).

Besides, the capacity of microorganisms to evolve resistance to antimicrobials, their ability to form biofilms allows the development of severe infections with high morbidity and mortality. Biofilms are structured microorganism communities surrounded by an extracellular matrix (EM) adhered to abiotic or biological surfaces, which favor the survival of the microorganisms, especially in hostile environments. Also, biofilm protects bacterial cellsfrom the host immune system. It increases the tolerance to antimicrobial therapy, as it prevents the penetration of most antimicrobial drugs into the EM, which requires higher doses that are practically impossible to achieve in vivo due to their inherent toxicity (Lima et al. 2018, Maurice et al. 2017, Kamali et al. 2020).

The treatment of biofilms requires a better understanding of the mechanisms of action of each antimicrobial, especially its ability to cross the EM. $\beta$-lactams are the drugs of choice to treat infections caused by MDR P. aeruginosa isolates, while polymyxins are the last therapeutic option for XDR isolates. However, both are not effective in crossing the EM, therefore not being ideal options for infections associated with biofilm. The combined therapy with azithromycin
(AZT) can bypass this problem since this drug dysregulates bacterial quorum sensing (QS) and reduces biofilm formation. These effects enhance $\beta$-lactams and polymyxins penetration into the $E M$, making them more effective against the microorganisms (Brackman et al 2011, Xu et al. 2015).

To understand how these bacteria respond to antimicrobials, nanotechnological tools, such as quantum dots (QDS), have been used (Luo et al. 2011, Li et al. 2020). QDs are fluorescent semiconductor nanocrystals that have unique properties, such as high resistance to photodegradation and active surface for conjugation with molecules, such as proteins and drugs. Consequently, the conjugation of QDs to drugs can be used to evaluate the effect of these drugs on bacterial cells using a single nanoprobe (Li et al. 2020).

Another promising tool for assessing protein changes of microorganisms in response to antimicrobials is mass spectrometry by matrix-assisted laser desorption/ionization time-of- flight (MALDI-TOF MS). The use of MALDITOF MS has become an excellent tool to identify microbials. Besides, it has a high potential for conducting a rapid investigation of antimicrobial resistance. This tool generates spectra, in which ribosomal proteins appear with molecular mass ranging from 2 to $20 \mathrm{kDa}$, which can be an advantage since can be used as biomarkers. The identification of microorganisms, as well as the analysis of antimicrobial resistance using the MALDI-TOF MS technique, occurs through the comparison between the acquired spectra with reference spectra included in the microorganism database of collections of cultures from all over the world (Roberto et al. 2020).

Therefore, the present study aimed to evaluate the occurrence of $\beta$-lactamases and quorum sensing (QS) genes in CRPA isolates, analyze the phenotypic production of biofilm. In 
addition, we evaluated the response of a clinical strain of CRPA carrying the blaKPC gene and biofilm-producing against monotherapy with MPM or POL B and its association with AZT using QDS and the MALDI-TOF MS analysis.

\section{MATERIALS AND METHODS}

\section{Bacterial isolates and Source}

The bacteria analyzed in this study were isolated from patients admitted in a public hospital from Recife, Pernambuco, Brazil. The samples were provided by the bacteriology division of the hospital over the year 2016. This study was approved by the Human Research Ethics Committee of the Federal University of Pernambuco, Brazil (CEP 1.480.085).

Six carbapenem-resistant $P$. aeruginosa strain from spontaneous demand samples were included in the study. The isolates were stored at $-20{ }^{\circ} \mathrm{C}$ in Bacteriology and Molecular Biology Laboratory, Universidade Federal de Pernambuco. The frozen isolates were reactivated in brain heart infusion ( $\mathrm{BHI}$ ) broth and incubated for $24 \mathrm{~h}$ at $37^{\circ} \mathrm{C}$, and then seeded cetrimide agar and incubated for $24 \mathrm{~h}$ at $37^{\circ} \mathrm{C}$. These isolates were diverse clinical samples.

\section{Phenotypic biofilm detection}

The six isolates were evaluated phenotypically for biofilm production using the quantitative technique (Stepanovic et al. 2000), with modifications. Briefly, $50 \mathrm{~g} \cdot \mathrm{L}^{-1}$ sucrose was added to BHI broth (Lima et al. 2018). The categorization of biofilm production was performed according to the biomass adhered to the bottom of the plate according to the values of the optical densities read at $570 \mathrm{~nm}$. The $\mathrm{BHI}$ broth was used as the negative control (CN) and the P. aeruginosa strain PA01 was used as the positive control (CP) since this strain is recommended as a positive control for biofilm assays.

\section{Detection of QS genes}

Thetotal DNA of the isolates was extracted utilizing the Brazol kit (LGC Biotecnologia), according to the protocol provided by the manufacturer. After extraction, DNA quantification was performed by spectrophotometry (Ultraspec 3000; Pharmacia Biotech) over the wavelength range from 260 to $280 \mathrm{~nm}$. Polymerase chain reactions (PCR) were performed for detecting QS genes: lasl, lasR, rhll, and rhlR (Lima et al. 2018), the primers used are listed in Table I. The parameters used for the amplifications of QS genes were 30 cycles of denaturation at $94^{\circ} \mathrm{C}$ for $1 \mathrm{~min}$, annealing at 52 ${ }^{\circ} \mathrm{C}$ for $1 \mathrm{~min}$, and extension at $72{ }^{\circ} \mathrm{C}$ for $1.5 \mathrm{~min}$. The PCR products were stained with Blue Green Loading Dye I (LGC Biotecnologia - São Paulo), submitted to $2 \%$ agarose gel electrophoresis, and visualized under UV light.

\section{Detection of M $\beta$ L genes (blaSPM-1, blaIMP, blavIM) and blaKPC}

To elucidate the mechanism of resistance to $\beta$-lactams in CRPA isolates, the genes of metallo- $\beta$-Lactamases (M $\beta$ LS) and blaKPC were searched using specific primers (Jacomé et al. 2016), also listed in Table I. For each PCR, a negative control was added containing all compounds used in the reaction without DNA. In addition, the positive control strains for the genes: blasPM-1 (P. aeruginosa 48-1997A), blaIMP (P. aeruginosa PSA319), and blaVIM (P. aeruginosa VIM-1) supplied by the Laboratory Alert from the Federal University of São Paulo (UNIFESP) and blaKPC ( $P$. aeruginosa P22A) from the culture collection of the Laboratory of Bacteriology and Molecular Biology, Department of Tropical Medicine, Federal University of Pernambuco (UFPE). 
Table I. Primers used in the detection of $\beta$-lactamases and QS genes.

\begin{tabular}{|c|c|c|c|c|}
\hline Gene & Primer & Sequence $\left(5^{\prime}-3^{\prime}\right)$ & $\begin{array}{c}\text { Annealing } \\
\text { temperature }\left({ }^{\circ} \mathrm{C}\right)\end{array}$ & $\begin{array}{l}\text { Number } \\
\text { of cycles }\end{array}$ \\
\hline$b^{b l a} a_{K P C}$ & KPC-1a KPC-1b & TGTCACTGTATCGCCGTC CTCAGTGCTCTACAGAAAACC & 63.0 & 35 \\
\hline$b_{\text {la }} a_{\text {SPM-1 }}$ & SPM-1 F SPM-1 R & CCTACAATCTAACGGCGACC TCGCCGTGTCCAGGTATAAC & 55.3 & 30 \\
\hline$b^{b l a}{ }_{I M P}$ & IMP-F IMP-R & $\begin{array}{l}\text { GGAATAGAGTGGCTTAATTCTC } \\
\text { GTGATGCGTCYCCAAYTTCACT }\end{array}$ & 50.6 & 30 \\
\hline bla $_{\mathrm{vIM}}$ & VIM-F VIM-R & CAGATTGCCGATGGTGTTTGG AGGTGGGCCATTCAGCCAGA & 56.8 & 30 \\
\hline lasR & $\begin{array}{l}\text { lasR-F } \\
\text { lasR-R }\end{array}$ & $\begin{array}{l}\text { AAGTGGAAAATTGGAGTGGAG } \\
\text { GTAGTTGCCGACGACGATGAAG }\end{array}$ & 52 & 30 \\
\hline lasl & $\begin{array}{l}\text { lasl-F } \\
\text { lasl-R }\end{array}$ & $\begin{array}{l}\text { CGTGCTCAAGTGTTCAAGG } \\
\text { TACAGTCGGAAAAGCCCAG }\end{array}$ & 52 & 30 \\
\hline rhlR & $\begin{array}{l}\text { rhlR-F } \\
\text { rhlR-R }\end{array}$ & $\begin{array}{l}\text { TGCATTTTATCGATCAGGGC } \\
\text { CACTTCCTTTTTCCAGGACG }\end{array}$ & 52 & 30 \\
\hline rhll & $\begin{array}{l}\text { rhll-F } \\
\text { rhll-R }\end{array}$ & $\begin{array}{l}\text { TTCATCCTCCTTTAGTCTTCCC } \\
\text { TTCCAGCGATTCAGAGAGC }\end{array}$ & 52 & 30 \\
\hline
\end{tabular}

\section{Synthesis of CdTe QDs and Conjugation of QDs to meropenem}

The synthesis of QDs and the conjugation of QDS to meropenem were performed following the protocols previously described by (Cabral Filho et al. 2016, Silva Júnior et al. 2020). Then, a CRPA $P$. aeruginosa (JX05) isolate carrying the blaKPC gene and biofilm- producing was selected to be incubated with the QDS-MPM conjugate to evaluate, by fluorescence microscopy, the effect of the association with the AZT on the bacterial cells.

\section{Bacterial inoculum and labeling with the QDs- MPM conjugate}

To confirm the inoculum purity, the P. aeruginosa clinical isolate JX05 was grown on Cetrimide agar, and single colonies were then inoculated in 2 $\mathrm{mL}$ of Luria Bertani (LB) broth and incubated at $37^{\circ} \mathrm{C}$ for $24 \mathrm{~h}$. For the labeling experiments, the inoculum was adjusted to $0.5 \mathrm{McFarland}$. Before bacterial labeling experiments, the remaining activated carboxyl groups of the QDs conjugates
$(500 \mu \mathrm{L})$ were blocked using $25 \mu \mathrm{L}$ Tris base (15 $\mathrm{mg} \mathrm{mL}^{-1}$ ), according to (Silva Júnior et al. 2020).

\section{Effect of the QDs conjugates on the bacterial growth}

To assess the effectiveness of the bacterial labeling by QDS-MPM conjugates, the inoculum $(50 \mu \mathrm{L})$ and the QDs-MPM conjugates suspension $(50 \mu \mathrm{L})$ were added in a $0.5-\mathrm{mL}$ microtube. The microtube was kept under constant agitation for $1 \mathrm{~h}$ at $25^{\circ} \mathrm{C}$, and after this period, two successive washes were performed by centrifuging the microtube at 1,400 $\times$ g for $5 \mathrm{~min}$. Then, the pellet was resuspended in $\mathrm{NaCl} 0.9 \%$ (w/v - from now on named as saline solution) and observed using an inverted fluorescence microscope (DMI4000B) (Leica Microsystems, Germany) at $63 \times$ objective with numerical aperture of 1.25 . The fluorescence of conjugates was observed using the excitation and emission band pass (BP) filters $560 / 40 \mathrm{~nm}$ and 645/75 nm, respectively (Silva Júnior et al. 2020).

A second procedure was performed to increase the formation of bacterial aggregates in 
the presence of an excess of MPM. The inoculum $(50 \mu \mathrm{L})$ and the QDs-MPM conjugate suspension $(50 \mu \mathrm{L})$ were incubated together as in the previous experiment, but an additional $50 \mu \mathrm{L}$ of MPM ( $1 \mathrm{mg} \cdot \mathrm{mL}^{-1}$ ) was added to the microtube (Silva Júnior et al. 2020). The microtube was kept under constant agitation for $1 \mathrm{~h}$ at $25^{\circ} \mathrm{C}$. The same washing and resuspension procedures described above were used. As a negative control, the bacterial inoculum without any treatment was evaluated and also using only bare QDs.

\section{Effect of the association of the QDs-MPM conjugates with azithromycin}

To evaluate the effects of disrupting the QS on the bacterial aggregation, $50 \mu \mathrm{L}$ of AZT ( $1 \mathrm{mg} \cdot \mathrm{mL}^{-1}$ ) was added to the inoculum previously incubated for $1 \mathrm{~h}$ with the QDS-MPM and the excess of MPM (second procedure). Then, the system was incubated for another $30 \mathrm{~min}$ at $25^{\circ} \mathrm{C}$. After this second incubation period, the same washings and resuspension procedures, using saline solution, were followed as described in the previous tests. These analyzes were performed in triplicate (Silva Júnior et al. 2020).

\section{Proteomic analysis by MALDI-TOF MS}

The effect of antibiotics on the protein composition of the $P$. aeruginosa clinical isolate JX05 was determined by MALDI-TOF MS.
For this purpose, the inoculum was prepared as described in the previous experiments and then treated with MPM, POL B, AZT, and their association, as shown in Table II. These analyzes were performed in triplicate.

The inocula were treated with MPM and/ or POL B and kept under constant agitation for $1 \mathrm{~h}$ at $25^{\circ} \mathrm{C}$. For the groups that also received AZT, after this first incubation period, this antimicrobial was added and the samples were incubated for an additional $30 \mathrm{~min}$ at $25^{\circ} \mathrm{C}$ under constant agitation. Then, samples were centrifuged at 9,000 $\times$ g for $5 \mathrm{~min}$, and the pellet was washed three times with $50 \mu \mathrm{L}$ of ultra-pure water. One microliter of the samples was directly spotted in duplicate on a polished steel target plate (Bruker Daltonics, MA, USA). Then, samples were covered with $\alpha$-cyano-4-hydroxycinnamic acid (CHCA) matrix solution $(75 \mathrm{mg} / \mathrm{mL}$ of $\mathrm{CHCA}$ matrix in ethanol/water/acetonitrile [1:1:1] with $0.03 \%$ trifluoroacetic acid) and dried (Cordeiro et al. 2017).

Mass spectra were acquired using a MALDITOF MS Autoflex III smart bean mass spectrometer (Bruker Daltonics, Bremen, Germany) equipped with a 1,064 nm Nd:YAG laser, in the positive reflector mode, and laser frequency of $100 \mathrm{~Hz}$. MS spectra were acquired at 400-2000 m/z range using the Flex Control software (version 3.3, Bruker). The spectra were processed using the Flex Analysis software (version 3.3, Bruker).

Table II. Experimental groups used for proteomic analyses. The antibiotics were dissolved at $1 \mathrm{mg} \cdot \mathrm{mL}^{-1}$.

\begin{tabular}{|c|c|}
\hline Groups & Treatments \\
\hline $\mathbf{1}$ & $50 \mu \mathrm{L}$ of the inoculum without any treatment (negative control) \\
\hline $\mathbf{2}$ & $50 \mu \mathrm{L}$ of the inoculum $+50 \mu \mathrm{L}$ of AZT \\
\hline $\mathbf{3}$ & $50 \mu \mathrm{L}$ of the inoculum $+50 \mu \mathrm{L}$ of $\mathrm{MPM}$ \\
\hline $\mathbf{4}$ & $50 \mu \mathrm{L}$ of the inoculum $+50 \mu \mathrm{L}$ of POL B \\
\hline $\mathbf{5}$ & $50 \mu \mathrm{L}$ of the inoculum $+50 \mu \mathrm{L}$ of MPM and $50 \mu \mathrm{L}$ of AZT \\
\hline $\mathbf{6}$ & $50 \mu \mathrm{L}$ of the inoculum $+50 \mu \mathrm{L}$ of POL B and $50 \mu \mathrm{L}$ of AZT \\
\hline $\mathbf{7}$ & $50 \mu \mathrm{L}$ of the inoculum $+50 \mu \mathrm{L}$ of MPM, $50 \mu \mathrm{L}$ of POL B, and $50 \mu \mathrm{L}$ of $\mathrm{AZT}$ \\
\hline
\end{tabular}


Besides, the spectra obtained from different treatments were compared among them using the MMass software version 5.5, an Open Source Mass Spectrometry Tool (Strohalm et al. 2010). To compare the peak list, the data were processed using the following tools: peak picking, baseline correction, and smoothing, according to (Niedermeyer \& Strohalm 2012).

Afterward, selected parent ions were fragmented using LIFT mode. The sequences were compared with the protein database of the National Centre for Biotechnology Information (NCBI, MD, USA), BioPep (Iwaniak et al. 2016), and UniProt (Bateman et al.2019).

\section{RESULTS}

\section{Origin of isolates}

The six CRPA isolates from samples of tracheal secretion, blood and urine were evaluated, with the most frequent sample being tracheal secretion with $66.7 \%(4 / 6)$, as can be seen in Table III.

\section{Biofilm detection}

The six isolates studied were biofilm producers, besides, all were classified as strongly adherent as demonstrated in Table III.

\section{Detection of QS, M $\beta L$ (blaSPM-1, blaIMP, blavIM) and blaKPC genes}

All six CRPA isolates displayed the four studied QS genes (lasl, lasR, rhll, rhlR). Of the six CRPA isolates analyzed in this study, none had genes related to $M \beta L$, however, 66.7\% (4/6) were positive for the presence of the blaKPC gene, Table III.

\section{Evaluation of biofilm formation by QDs-MPM conjugates}

Untreated bacteria did not show any fluorescence when excited using the filter 560/40 nm (Fig. 1a). After incubating the P. aeruginosa clinical isolate JX05 with the QDS-MPM conjugates, rare isolated cells, and small bacterial aggregates (microcolonies) labeled by the conjugate were observed (Fig. 1b), which proves the feasibility of using this tool. Then, a second experiment was carried out, in which the clinical isolate JX05

Table III. Phenotypic and genetic characterization of CRPA isolates.

\begin{tabular}{|c|c|c|c|c|c|c|c|c|c|c|c|}
\hline Isolate & $\begin{array}{c}\text { Susceptibility } \\
\text { profile }\end{array}$ & Source & $\begin{array}{c}\text { Adhesion profile of } \\
\text { biofilm }\end{array}$ & las $R$ & lasl & rhlR & rhll & KPC & SPM-1 & VIM & IMP \\
\hline JM01 & MDR & $\begin{array}{c}\text { Tracheal } \\
\text { secretion }\end{array}$ & Strongly adherent & + & + & + & + & - & - & - & - \\
\hline JM02 & MDR & $\begin{array}{c}\text { Tracheal } \\
\text { secretion }\end{array}$ & Strongly adherent & + & + & + & + & - & - & - & - \\
\hline JX03 & XDR & $\begin{array}{l}\text { Tracheal } \\
\text { Secretion }\end{array}$ & Strongly adherent & + & + & + & + & + & - & - & - \\
\hline JX04 & XDR & Blood & Strongly adherent & + & + & + & + & + & - & - & - \\
\hline JX05 & XDR & $\begin{array}{l}\text { Tracheal } \\
\text { Secretion }\end{array}$ & Strongly adherent & + & + & + & + & + & - & - & - \\
\hline JX06 & XDR & Urine & Strongly adherent & + & + & + & + & + & - & - & - \\
\hline
\end{tabular}


was incubated with the QDS-MPM conjugates supplemented with an excess of free MPM. The extra MPM induced the formation of large bacterial aggregates, suggesting that biofilm formation is the first response of this clinical isolate JX05 to the stress caused by MPM (Fig. 1c). Then, when the treatment with AZT was combined, it disrupted the biofilm formation, and only free bacteria (planktonic cells) was seen, demonstrating that the association of AZT with MPM is capable to impair the biofilm formation in this CRPA clinical isolate (Fig. 1d).

\section{Proteomic analysis by MALDI-TOF MS}

The analysis of the MS of the untreated $P$. aeruginosa clinical isolate JX05 (negative control) showed several peaks with $\mathrm{m} / \mathrm{z}$ between 400.000 and 1,264.420 Da as showed in Fig. 2a. The treatment with AZT (treatment 2) did not change the mass spectra pattern (Fig. 2b). However, the comparative analysis of the mass spectra acquired for the bacteria treated with MPM (treatment 3 - Fig. 2C), POL B (treatment 4), MPM + AZT (treatment 5), POL B + AZT (treatment 6), and MPM + POL B + AZT (treatment 7) revealed the suppression of two peaks at 1,151.450 and 1,264.420 Da. MS/MS analysis of the
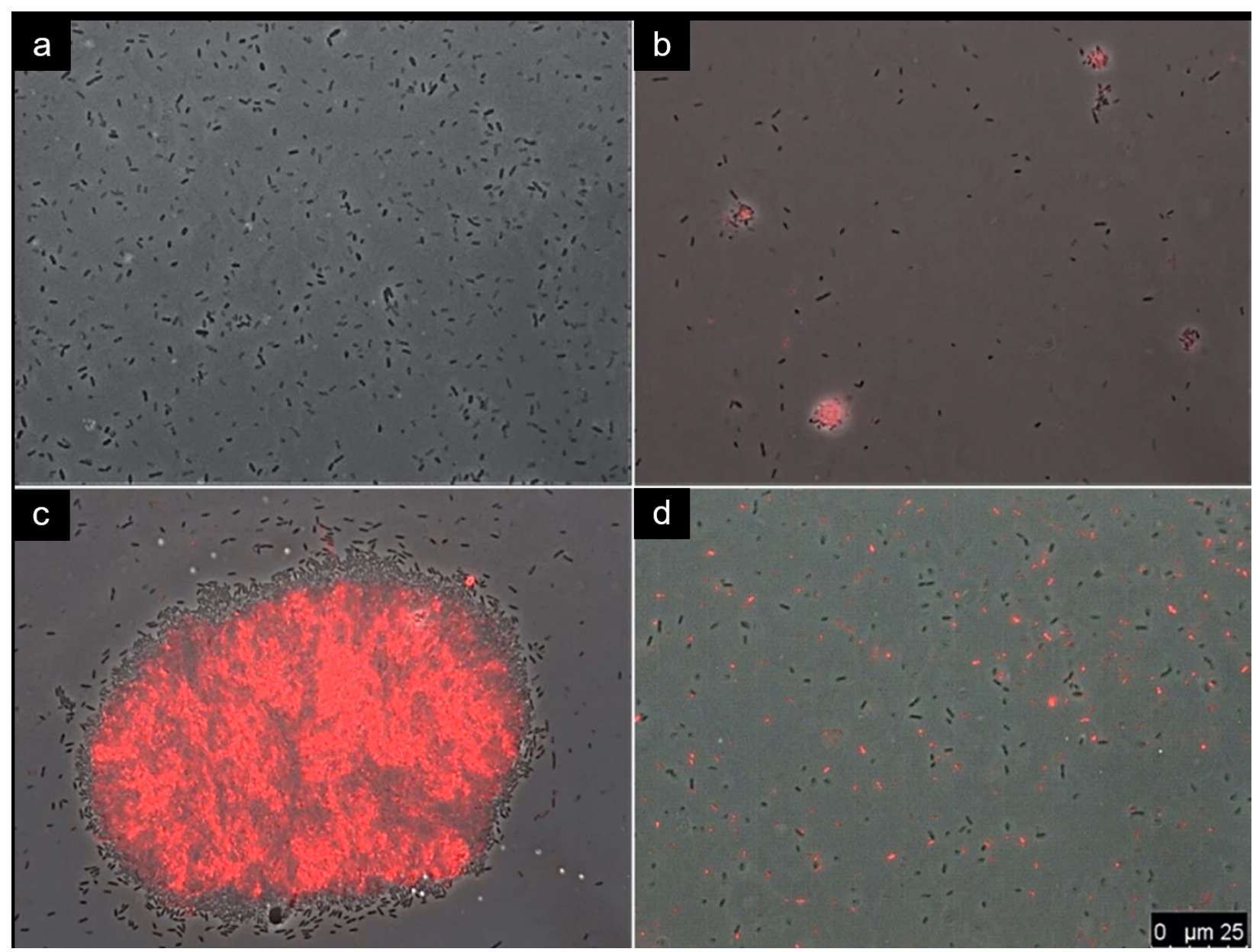

Figure 1. Representative fluorescence microscopy images of JX05 clinical isolate. (a) Untreated bacteria; (b) Bacteria treated with QDs-MPM conjugates; (c) Bacteria treated QDs-MPM conjugates and an excess of free MPM, and (d) Bacteria treated with QDs-MPM conjugate and an excess of free MPM, combined with AZT. Micrographs show the overlapping of fluorescence (BP 645/75 nm) and phase-contrast images. Scale bar: $25 \mu \mathrm{m}$. 
peak 1,264.420 Da revealed the following amino acid sequence: glutamic acid-lysine-threonineproline-glycine-proline-valine-tyrosine-glycine, which showed $100 \%$ similarity with the protein transglycosylase, as indicated by $P$. aeruginosa taxonomy id:287 database ( $P$. aeruginosa ATCC 10145), accession number: EVT86745.1, Table IV.

In the mass spectra of the clinical isolate JX05 treated with the association of MPM + AZT (treatment 5), POL B + AZT (treatment 6), and
MPM + POL B + AZT (treatment 7), a different peak appeared at 972.389 Da. MS/MS analysis revealed the following amino acid sequence: glycine-methionine-arginine-glutamic acidmethionine-lysine-glutamine, which showed $100 \%$ similarity with the protein RpoN (054), as indicated by $P$. aeruginosa taxonomy id:287 database ( $P$. aeruginosa ATCC 10145), NCBI Reference Sequence IDWP_047150239.1, Table IV. (a)

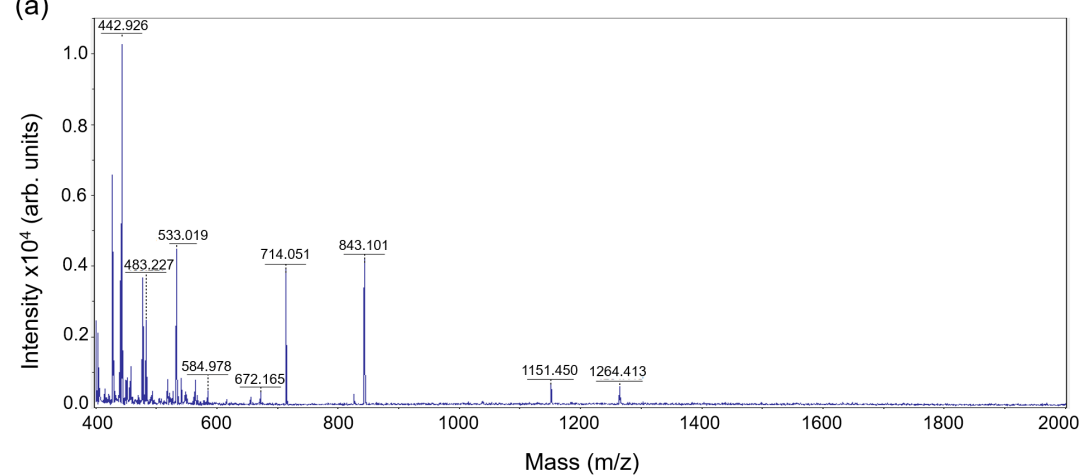

(b)

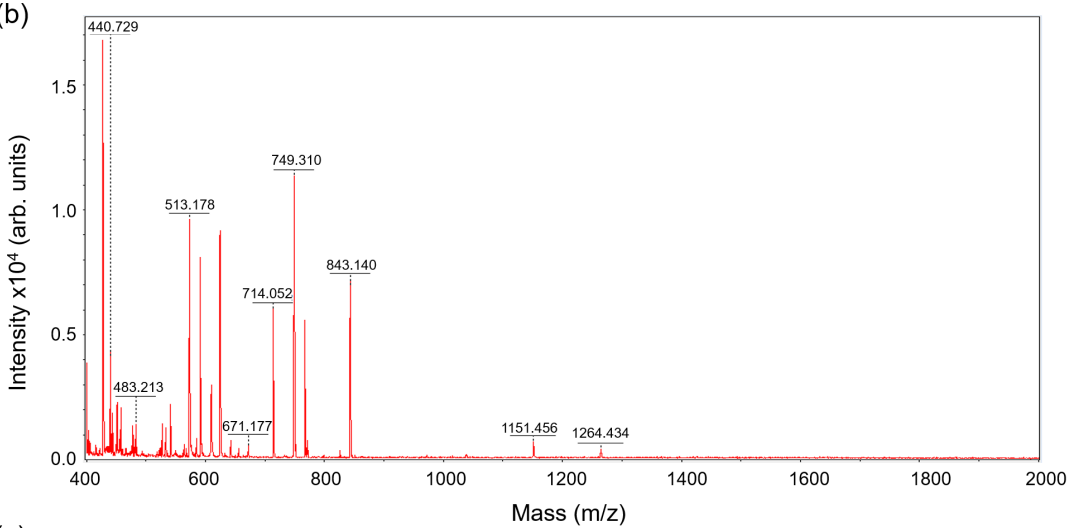

(c)

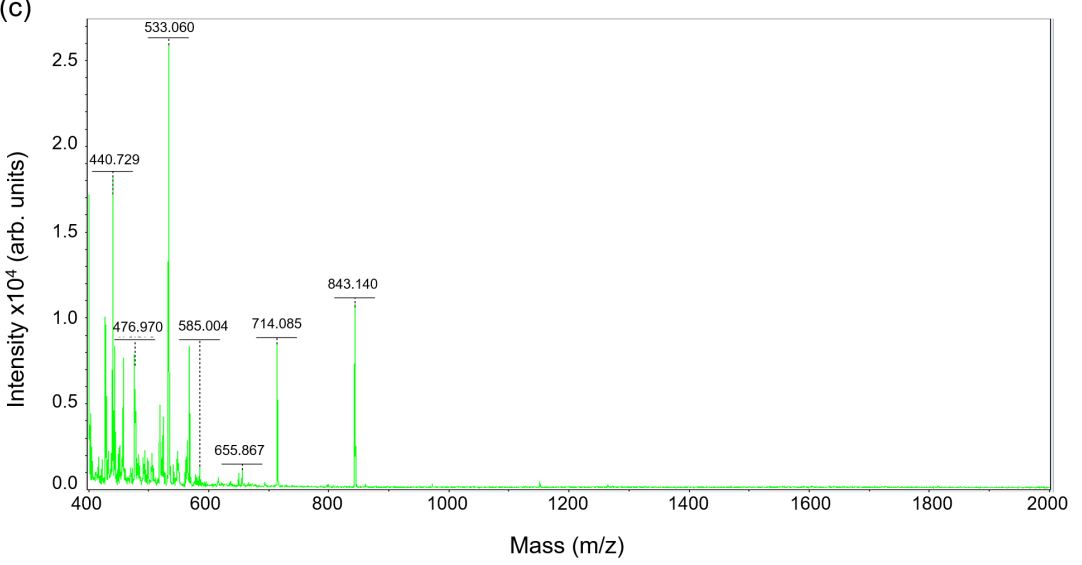

Figure 2. Effect of antibiotics on the protein composition of $P$. aeruginosa JX05 isolate obtained from MALDI TOF mass spectrometry. In (a) only $P$. aeruginosa JX05 bacterial strain; (b) P. aeruginosa after treatment with AZT and (c) $P$. aeruginosa after treatment with MPM. arb. units is arbitrary units. 
Table IV. Analysis of expression (+) and suppression (-) of transglycosylase and RpoN proteins against different antimicrobial treatments in P. aeruginosa JX05 isolate by MALDI-TOF MS.

\begin{tabular}{|l|c|c|c|c|c|c|c|}
\hline Treatments & $\mathbf{1}$ & $\mathbf{2}$ & $\mathbf{3}$ & $\mathbf{4}$ & $\mathbf{5}$ & $\mathbf{6}$ & $\mathbf{7}$ \\
\hline Transglycosylase & + & + & - & - & - & - & - \\
\hline RpoN & - & - & - & - & + & + & + \\
\hline
\end{tabular}

\section{DISCUSSION}

Most of the CRPA isolates analyzed in this study were obtained from samples of tracheal secretion, data that corroborate the findings described in the literature that brings this $P$. aeruginosa as one of the main microorganisms related to lower respiratory tract infections (Lima et al. 2018).

In this study, the phenotypic test used to analyze biofilm formation by CRPA isolates demonstrated biofilm production by all isolates, which were classified as strong producers. These findings corroborate other studies that used the same technique to analyze the production of biofilm by this same microorganism, obtaining high production of biofilm among the analyzed (Perez et al. 2013, Lima et al. 2017, 2018, Kırmusaoğlu \& Yurdugül 2017).

The formation of biofilm is a multifactorial process and is regulated by different genes related to the QS (Lima et al. 2018). The presence of QS genes associated with the detection of biofilm formation by the isolates can help in the evaluation of the regulation of the expression of these genes. In this study, the presence of QS genes was found in all analyzed CRPA isolates, corroborating the data obtained in other studies that detected a high occurrence of them (Perez et al. 2013, Kırmusaoğlu \& Yurdugül 2017, Lima et al. 2018).

Different enzymes may be related to the development of resistance among CRPA isolates, in this study, a high occurrence of the blaKPC gene was found among the analyzed isolates, data that corroborate the results obtained in other studies (Jacomé et al. 2016, Scavuzzi et al. 2019).

The increase of MPM-resistant bacteria is a serious public health problem even if high doses of MPM are still effective against planktonic bacteria. However, the formation of biofilm hinders the action of this antimicrobial in the microorganism (Song et al 2019).

In our study, the KPC-positive $P$. aeruginosa clinical isolate JX05 responded to the stress caused by the highest concentration of MPM in producing biofilm. Besides, (Perez et al. 2013), demonstrated that $P$. aeruginosa isolates metallo- $\beta$-lactamase producer had a higher ability to induce biofilm formation, mainly those carrying the QS genes, also being observed in the CRPA isolates in this study harboring the QS and blaKPC genes.

The biofilm extracellular matrix (EM) hinders most antibiotics from reaching the bacterial cells, making therapeutic doses ineffective (Olivares et al. 2020). Consequently, the release of $\beta$-lactamase enzyme KPC by the $P$. aeruginosa clinical isolate JX05 in the EM of the biofilm in formation helps in the tolerance of this isolate to MPM, which induced the formation of large bacterial aggregates. This result demonstrates the role that different resistance and virulence factors play in bacterial resistance (Bowler et al. 2012, Olivares et al. 2020).

In this study, QDs were used as probes conjugated to MPM to evaluate the response of a biofilm-producing CRPA isolate to different 
therapies, which has shown to be a promising tool. Corroborating the results obtained by (Luo et al. 2011), they used QDs as probes to evaluate the effect of the antimicrobial rocephin against Escherichia coli and obtained good results. Similar data were observed in the study in which the activity of the antimicrobial peptide indolicidin (Ind) was evaluated using QDS against Staphylococcus aureus (ATCC 6538), P. aeruginosa (ATCC 1025), E. coli (ATCC 11229), and Klebsiella pneumoniae (ATCC 10031) (Galdiero et al. 2016). Although the studies mentioned here show the effects of drugs when conjugated with QDs, it is essential to reinforce that all these combinations were tested against microorganisms with high susceptibility to antimicrobials. Different from our study, in which is the first to use QDs conjugated with MPM and combined therapy with AZT for $P$. aeruginosa strain with blaKPC gene and a high degradation power of antimicrobials agents. The MPM tolerance of this clinical isolate may be associated with the release of the $\beta$-lactamases (KPC) enzyme in the extracellular matrix of the biofilm formed, which corroborates the data obtained by (Bowler et al. 2012).

QD-MPM was already used previously by our group to trigger the biofilm formation and also revealed the role of an efflux pump inhibitor, the CCCP (carbonyl cyanide-3chlorophenylhydrazone), in an MDR P. aeruginosa strain (Silva Júnior et al. 2020). Authors analyzed a clinical isolate of $P$. aeruginosa (P118) carrying the blaGES-1 gene (a clinically relevant extendedspectrum $\beta$-lactamase (ESBL), that hydrolyzes penicillins and broad-spectrum cephalosporins but spares monobactams and carbapenems) using the QDS-MPM conjugates. Their results demonstrated that this probe was efficient to label this microorganism making it possible to visualize the formation of bacterial aggregates in response to treatment with MPM. They also verified using QDS-MPM the effect of CCCP on a $P$. aeruginosa (MDR) strain, which was able to inhibit the efflux pump of this microorganism, increasing the susceptibility of this isolate (Silva Júnior et al. 2020).

Herein, we also confirmed the effectiveness of the QDS-MPM conjugates in bacterial tolerance to antimicrobials and the effect of the association of drugs in XDR P. aeruginosa strain (Fig. 1 b-d). To our knowledge, this is the first study that used QDS-MPM in an XDR $P$. aeruginosa (JX05) strain carrying the blaKPC gene, which confers resistance to all $\beta$ - lactams, including carbapenems, and explored the combination therapy using AZT and QDs- MPM.

In this context, AZT has been proven as an effective alternative to impair adhesion and biofilm formation of $P$. aeruginosa in abiotic surfaces (Xu et al. 2015). Accordingly, with our results, in which $A Z T$ was associated with the QD-MPM conjugates, the effectiveness of AZT in inhibiting QS has been proven, preventing the formation of bacterial aggregates (Fig. 1d).

Examination of protein profiles by proteomic analysis has become an important tool for the study of bacterial resistance and the understanding of the biology of the proteomic response of pathogens is generally specific to each antibiotic (Pérez-Llarena \& Bou 2016). Our data related to proteomic analysis employing MS showed that treatments with MPM or POL $B$ suppressed the expression of lytic protein transglycosylases (LTs), while treatments with $M P M+A Z T$ (treatment 5), POL B + AZT (treatment 6) and MPM + POL B + AZT (treatment 7) resulted in the expression of RpoN protein ( 054 ).

RpoN is required by several genes involved in many functions, such as; the production of extracellular elements, different resistance mechanisms, and virulence factors, which are needed to adjust in a variety of environmental conditions (Yamano et al. 1998). Besides, 
RpoN protein regulates genes related to the QS in P. aeruginosa, reducing the cellular metabolism and triggering the tolerance of this microorganism to MPM (Viducic et al. 2016). Another study of the same research group showed that the RpoN protein promoted the survival of $P$. aeruginosa when it was treated with tobramycin, favoring therapeutic tolerance (Viducic et al. 2017). On the other hand, the inhibition of the RpoN protein in P. aeruginosa clinical isolates reduces the virulence and resistance of these bacteria (Lloyd et al. 2019, 2017).

Moreover, according to the MS, lytic transglycosylasesf were inhibited after the incubation of bacterial cells with MPM or POL B. These LTS are responsible for catalyzing the non-hydrolytic cleavage of the peptidoglycan structures of the bacterial cell wall. Besides, the LTs play important roles in different pathways, including (i) cell wall synthesis, remodeling, and degradation; (ii) detection of antibiotics which act on the cell wall; and (iii) expression of resistance mechanisms to antibiotics that act on the cell wall by certain Gram- negative bacteria (Dik et al. 2017).

$P$. aeruginosa strains mutants for genes related to the transglycosylase enzyme cause the highest level of resistance to these pathogens, and loss of specific transglycosylase in $P$. aeruginosa increased $\beta$-lactam sensitivity (Cavallari et al. 2013), suggesting that transglycosylase enzyme may be a target for antimicrobial adjuvants (Lamers et al. 2015).

Suppression of mutation in genes that encoding LTs in $P$. aeruginosa increase biofilm production, a mechanism capable of compensating the absence of this protein (Lamers et al. 2015). This explains the formation of large bacterial aggregates when the CRPA clinicalisolate (JX05) was treated with MPM conjugated with QDs as observed by the fluorescent images (Fig. $1 \mathrm{~b}$ and 1c). We also observed the absence of LTs in this same system (treatment 3) when it was analyzed by MS.

Biofilm formation impacts P. aeruginosa resistance to $\mathrm{POL} B$ since it interferes with the penetration of this drug (Da Silva Carvalho \& Rodriguez Perez 2019). In our study, it was found that the association between POL B + AZT (treatment 6) and MPM + POL B + AZT (treatment 7) resulted in the expression of the RpoN protein (654), a protein that is involved in the activation of different virulence and resistance mechanisms in this microorganism, also acting in the formation of biofilm and also regulates the susceptibility some antimicrobials including carbapenems in P. aeruginosa (Viducic et al. 2016, 2017).

Besides, to our knowledge, this is the first study that uses MS for proteomic analysis of a CRPA isolate, aiming to understand the tolerance of this microorganism through protein expression or/and suppression. This platform of analysis has become more and more relevant in clinical practice, allowing the phenotypic characterization and a dynamic analysis of the microorganisms behavior against antimicrobial therapy (Greco et al. 2018).

Therefore, through fluorescence and MS techniques, it was possible to observe the induction of biofilm formation from a CRPA carrying the blaKPC enzyme and the expression of proteins important to virulence and resistance mechanisms. In addition, the association of these two techniques was able to elucidate the mechanism of tolerance by this strain of CRPA to antimicrobials.

\section{CONCLUSIONS}

The clinical isolate of CRPA P. aeruginosa JX05 carrying the QS and blaKPC genes produced 
biofilm when treated with an excess of MPM, and the association with AZT inhibited this mechanism of resistance. Moreover, the treatment with MPM or POL B inhibited the production of LT enzyme. In contrast, the association of POL B or MPM with AZT, or both, induced the synthesis of the protein RpoN. These data show it is necessary to take into account the impact of bacterial virulence when choosing the best therapy for the treatment of infections, to avoid therapeutic failures and the increase in bacterial resistance.

In this study, QDs and MALDI TOF MS, two contrasting techniques were applied to evaluate the action of antimirobials in a biofilm-producing CPRA strain. We believe that researchers will be able to address these techniques to evaluate the effect of drugs in inhibiting biofilm formation of microorganisms with prospects of applicability in the biofilm therapy of resistant and virulent bacteria.

\section{REFERENCES}

BATEMAN A. 2019. UniProt: A worldwide hub of protein knowledge. Nucleic Acids Res.47(D1): D506-D515.

BRACKMAN G, COS P, MAES L, NELIS HJ \& COENYE T. 2011. Quorum sensing inhibitors increase the susceptibility of bacterial biofilms to antibiotics in vitro and in vivo. Antimicrob Agents Chemother 55(6): 2655-2661.

BOWLER LL, ZHANEL GG, BALL TB \& SAWARD LL. 2012. Mature Pseudomonas aeruginosa biofilms prevail compared to young biofilms in the presence of ceftazidime. Antimicrob Agents Chemother 56(9): 4976-4979.

CABRAL FILHO PE ET AL. 2016. CdTe quantum dots as fluorescent probes to study transferrin receptors in glioblastoma cells. Biochim Biophys Acta Gen Subj 1860(1): 28-35.

CORDEIRO RA ET AL. 2017. The HIV aspartyl protease inhibitor ritonavir impairs planktonic growth, biofilm formation and proteolytic activity in Trichosporon spp. Biofouling. 33(8): 640-650.

CAVALLARIJF,LAMERSRP,SCHEURWATEREM, MATOSAL\&BURROWS LL. 2013. Changes to its peptidoglycan-remodeling enzyme repertoire modulate $\beta$-lactam resistance in Pseudomonas aeruginosa. Antimicrob Agents Chemother 57(7): 3078-3084.

DA SILVA CARVALHO T \& RODRIGUES PEREZ LR. 2019. Impact of biofilm production on polymyxin B susceptibility among Pseudomonas aeruginosa clinical isolates. Infect Control Hosp Epidemiol 40(6): 739-740.

DIK DA, MAROUS DR, FISHER JF \& MOBASHERY S. 2017. Lytic transglycosylases: concinnityin concision of the bacterial cell wall. Crit Rev Biochem Mol. 52(5): 503-542.

DOI Y. 2019. Treatment Options for Carbapenem-resistan Gram-negative Bacterial Infections. Clin Infect Dis. 69(Suppl 7): S565-S575.

GALDIERO E ETAL. 2016. An integrated study on antimicrobial activity and ecotoxicity of quantum dots and quantum dots coated with the antimicrobial peptide indolicidin. Int J Nanomedicine. 11: 4199-4211.

GRECO V ET AL. 2018. Applications of MALDI-TOF mass spectrometry in clinical proteomics. Expert Rev Proteomics 15(8): 683-696.

HORCAJADA JP ET AL. 2019. Epidemiology and treatment of multidrug-resistant and extensively drug-resistant Pseudomonas aeruginosa infections. Clin Microbiol Rev 32(4): 1-52.

IWANIAK A, MINKIEWICZ P, DAREWICZ M, SIENIAWSKI K \& STAROWICZ P. 2016. BIOPEP database of sensory peptides and amino acids. Food Res Int 85: 155-161.

JACOMÉ PRLA ET AL. 2016. Detection of blaSPM-1, blaKPC, blaTEM and blaCTX-M genes in isolates of Pseudomonas aeruginosa, Acinetobacter spp. and Klebsiella spp. from cancer patients with healthcare-associated infections. J Medic Microbiol 5(7): 658-665.

KAMALI E, JAMALI A, ARDEBILI A, EZADI F \& MOHEBBI A. 2020. Evaluation of antimicrobial resistance, biofilm forming potential, and the presence of biofilm-related genes among clinical isolates of Pseudomonas aeruginosa. BMC Res Notes 13(1): 4-9.

KIRMUSAOĞLU S \& YURDUGÜL S. 2017. The effect of urinary catheters on microbial biofilms and cateter associated urinary tract infections. Miscellaneous 14(02): 3033.

LAMERS RP, NGUYEN UT, NGUYEN Y, BUENSUCESO RNC \& BURROWS LL. 2015. Loss of membrane-bound lytic transglycosylases increases outer membrane permeability and $\beta$-lactam sensitivity in Pseudomonas aeruginosa. Microbiology Open 4(6): 879-895.

LI P ET AL. 2020. Low-toxicity carbon quantum dots derived from gentamicin sulfate to combat antibiotic resistance 
and eradicate mature biofilms. Chem Commun 56(15): 2316-2319.

LIMA JLC, ALVES LR, PAZ JNP, RABELO MA, MACIEL MAV \& MORAIS MMC. 2017. Analysis of biofilm production by clinical isolates of Pseudomonas aeruginosa from patients with ventilator-Associated pneumonia. Rev Bras Ter Intensiva 29(3): 310-316.

LIMA JLC, ALVES LR, JACOMÉ PRLA, BEZERRA NETO JP, MACIEL MAV \& MORAIS MMC. 2018. Biofilm production by clinical isolates of Pseudomonas aeruginosa and structural changes in LasR protein of isolates non biofilmproducing. Braz J Infect Dis 22(2): 129- 136.

LOYD MG ET AL. 2017. Targeting the alternative sigma factor RpoN to combat virulencein Pseudomonas aeruginosa. Sci. Rep 7(1): 1-12.

LLOYD MG, VOSSLER JL, NOMURA CT \& MOFFAT JF. 2019. Blocking RpoN reduces virulence of Pseudomonas aeruginosa isolated from cystic fibrosis patients and increases antibiotic sensitivity in a laboratory strain. Sci Rep 9(1): 1-10.

LUO Z, WU Q, ZHANG M, LI P \& DING Y. 2011. Cooperative antimicrobial activity of CdTe quantum dots with rocephin and fluorescence monitoring for Escherichia coli. J Colloid Interface Sci 362(1): 100-106.

MAURICE NM, BEDI B \& SADIKOT RT. 2017. Pseudomonas aeruginosa biofilms: Host response and clinical implications in lung infections. Am J Respir Cell Mol Biol 58(4): 428-439.

MONTERO MM ET AL. 2019. Colistin plus meropenem combination is synergistic in vitro against extensively drug-resistant Pseudomonas aeruginosa, including high-risk clones. J Glob Antimicrob Resist 18: 37-44.

NIEDERMEYER THJ \& STROHALM M. 2012. mMass as a Software Tool for the Annotation of Cyclic Peptide Tandem Mass Spectra. PLOS ONE 7(9).

OLIVARES E, BADEL-BERCHOUX S, PROVOT C, PRÉVOST G, BERNARDI T \& JEHL F. 2020. Clinical Impact of Antibiotics for the Treatment of Pseudomonas aeruginosa Biofilm Infections. Front Microbiol 10: 1-12.

PEREZ LRR, MACHADO ABMP \& BARTH AL. 2013. The Presence of Quorum-Sensing Genes in Pseudomonas isolates Infecting Cystic Fibrosis and Non-cystic Fibrosis Patients. Curr Microbiol 66(4): 418-420.

PÉREZ-Llarena FJ \& BOU G. 2016. Proteomics as a tool for studying bacterial virulence and antimicrobial resistance. Front Microbiol 7: 1-21.
ROBERTO AEM, XAVIER DE, VIDAL EE, VIDAL CFL, NEVES RP \& LIMA-NETO RG. 2020. Rapid detection of echinocandins resistance by MALDI-TOF MS in Candida parapsilosis complex. Microorganisms 8(1): 1-13.

SCAVUZZI AML, BELTRÃO EMB, FIRMO EF, OLIVEIRA ÉM, BESERRA FG \& LOPES ACS. 2019. Emergence of blaVIM-2, blaNDM-1, blaIMP-7 and blaGES-1 in blaKPC-2 harbouring Pseudomonas aeruginosa isolates in Brazil. J Glob Antimicrob Resist 19: 181-182.

SILVA JÚNIOR VV ET AL. 2020. Activity of carbonyl cyanide3-chlorophenylhydrazone on biofilm formation and antimicrobial resistance in Pseudomonas aeruginosa using quantum dots-meropenem conjugates as nanotools. Methods Appl Fluoresc 1-6.

SONG X, WU Y, CAO L, YAO D \& LONG M. 2019. Is Meropenem as a Monotherapy Truly Incompetent for MeropenemNonsusceptible Bacterial Strains? A Pharmacokinetic/ Pharmacodynamic Modeling With Monte Carlo Simulation. Front Microbiol 10: 1-15.

STEPANOVIC S, VUKOVIC D, DAKICI, SAVIC B \& SVABIC-VLAHOVIC M. 2000. A modified microtiter-plate test for quantification of staphylococcal biofilm formation. J Microbiol Methods 115(8): 891-899.

STROHALM M, KAVAN D, NOVÁK P, VOLNÝ M \& HAVLIČCKE V. 2010. MMass 3: A cross-platform software environment for precise analysis of mass spectrometric data. Anal Chem 82(11): 4648-4651.

VIDUCIC D, MURAKAMI K, AMOH T, ONO T \& MIYAKE Y. 2016. RpoN modulates carbapenem tolerance in Pseudomonas aeruginosa through Pseudomonas quinolone signal and PqsE. Antimicrob Agents Chemother 60(10): 5752-5764.

VIDUCIC D, MURAKAMI K, AMOH T, ONO T \& MIYAKE Y. 2017. RpoN promotes Pseudomonas aeruginosa survival in the presence of tobramycin. Front Microbiol 8: 839.

XU ZG, GAO Y, HE JG, XU WF, JIANG M \& JIN HS. 2015. Effects of azithromycin on Pseudomonas aeruginosa isolates from catheter-associated urinary tract infection. Exp Ther Med 9(2): 569-572.

YAMANO Y, NISHIKAWA T \& KOMATSU Y. 1998. Involvement of the RpoN protein in the transcription of the oprE gene in Pseudomonas aeruginosa. FEMS Microbiol Lett 162(1): 31-37. 


\section{How to cite}

LIMA JLC, PEREIRA JNP, RAPOSO BL, FONTES A, CABRAL FILHO PE, LIMA NETO RG, XIMENES RM \& MACIEL MAV. 2021. Analyses of the response of carbapenem-resistant Pseudomonas aeruginosa against monotherapy and combined therapy using quantum dots and proteomics. An Acad Bras Cienc 93: e20210823. DOI 10.1590/0001-3765202120210823.

Manuscript received on June 4, 2021;

accepted for publication on August 24, 2021

JAILTON L.C. LIMA ${ }^{1}$

https://orcid.org/0000-0002-5500-1129

JUSSYÊGLES N.P. PEREIRA ${ }^{1}$

https://orcid.org/0000-0002-6494-0128

BRUNO L. RAPOSO 2

https://orcid.org/0000-0003-2107-9697

\section{ADRIANA FONTES ${ }^{2}$}

https://orcid.org/0000-0003-4675-2163

PAULO E. CABRAL FILHO ${ }^{2}$

https://orcid.org/0000-0002-1628-7769

REGINALDO G. LIMA NETO'

https://orcid.org/0000-0002-8846-877X

RAFAEL M. XIMENES ${ }^{3}$

https://orcid.org/0000-0002-2011-2865

MARIA AMÉLIA V. MACIEL ${ }^{1}$

https://orcid.org/0000-0002-4220-6889
Universidade Federal de Pernambuco, Coordenação de Área Medicina Tropical, Centro de Ciências Médicas, Av. Prof. Moraes Rego, 1235, CidadeUniversitária, 50670-901 Recife, PE, Brazil

${ }^{2}$ Universidade Federal dePernambuco, Departamento de Biofísica e Radiobiologia, Centro de Biociências, Av. Prof. Moraes Rego, 1235, Cidade Universitária, 50670-901 Recife, PE, Brazil

${ }^{3}$ Universidade Federal de Pernambuco,Departamento de Antibióticos, Centro de Biociências, Av. Prof. Moraes Rego, 1235, Cidade Universitária, 50670-901 Recife, PE, Brazil

\section{Correspondence to: Jailton Lobo da Costa Lima}

E-mail: jailtonlobo@hotmail.com

\section{Author contributions}

JLCL conceived and designed research, conducted experiments, analyzed data and wrote the manuscript. JNPP and BLR contributed new reagents or analytical tools. AF, PECF and RGLN contributed new reagents or analytical tools, analyzed data and wrote the manuscript. RMX analyzed data and wrote the manuscript. MAVM conceived and designed research, analyzed data and wrote the manuscript.

\section{(cc) BY}

